\title{
CORRIGENDUM
}

\section{Vacuum therapy in erectile dysfunction-science and clinical evidence}

J Yuan, AN Hoang, CA Romero, H Lin, Y Dai and R Wang

International Journal of Impotence Research (2010) 22, 290; doi:10.1038/ijir.2010.18

Correction to: International Journal of Impotence Research (2010) 22, 211-219 (this issue); doi:10.1038/ijir.2010.4; published online 22 April 2010

After the article was published online, the authors discovered a mistake in one of the manufacturer's details:
Mentor (Santa Barbara, CA, USA)

should appear as

Augusta Medical System (Augusta, GA, USA) 